\title{
Forum
}

\section{Schwerpunkt: Wie viel Medien-Öffentlichkeit verträgt die Demokratie?}

Die Enthüllungen des US-amerikanischen Whistleblowers Edward Snowden. Der Rücktritt Christian Wulffs vom Amt des Bundespräsidenten. Der „Arabische Frühling“ in Nordafrika und im Nahen Osten. In all diesen Fällen spielten die Medien eine zentrale Rolle: als Medium der Berichterstattung, als Hersteller von Öffentlichkeit, als Kontrolle der Mächtigen, als Mittel zur Skandalisierung.

Für Demokratien ist Medien-Öffentlichkeit essenziell. Medien gelten als „,vierte Gewalt“. Dabei geraten die Medien selbst immer stärker unter Druck, etwa durch zunehmende technische Möglichkeiten der Überwachung von Medien und Öffentlichkeit oder aufgrund vielfacher finanzieller Schwierigkeiten, die speziell im (Print-)Journalismus seit geraumer Zeit augenscheinlich sind. Die Rollenzuschreibung der Journalisten hat sich in der Bewertung der Öffentlichkeit verfinstert. Können Medien unter diesen Vorzeichen ihrem demokratischen Auftrag überhaupt noch gerecht werden? Führen nicht insbesondere die finanziellen Zwänge zu einer Aushöhlung des journalistischen Kerns der Medien, die über kurz oder lang in Boulevardisierung und Entertainisierung, in „Kampagnenjournalismus“ und temporären Erregungsöffentlichkeiten mündet? Oder bergen etwa die zunehmende Digitalisierung und Vernetzung nicht doch auch die Chance, sich auf die Kernaufgaben demokratischer Medien-Öffentlichkeit zu konzentrieren, wie beispielweise die jüngsten Veränderungen in der arabischen Welt oder die Enthüllungen um WikiLeaks und Edward Snowden suggerieren?

Vor diesem Hintergrund steht die Frage „Wie viel Medien-Öffentlichkeit verträgt die Demokratie?" im Zentrum des folgenden Forums. Otfried Jarren beschäftigt sich dabei aus der theoretischen Perspektive mit den Auswirkungen des Medienwandels auf Demokratie und Gesellschaft und fragt danach, inwiefern die Medien heute einen demokratischen Auftrag erfüllen. Aus dem Blickwinkel der politischen Systemforschung analysiert Ulrich Sarcinelli die gegenwärtige politische Berichterstattung. Kai Hafez beleuchtet abschließend aus der internationalen Perspektive den tatsächlichen Einfluss von Medien auf Demokratisierungsprozesse am Beispiel der „Arabellion“. 